\title{
El recurso de protección como recurso extraordinario: la sentencia de la corte suprema rol no 21.027-2019 y el futuro de la acción constitucional de protección
}

The action of Protection as an extraordinary procedural appeal: The Judgment of the Supreme Court role No 21.027-2019 and the future of the constitucional action of protection.

\section{Priscila Machado Martins ${ }^{1}$ \\ Universidad de los Andes pmachado@uandes.cl}

\begin{abstract}
Resumen: El presente artículo pretende analizar las consecuencias procesales que puede acarrear la jurisprudencia reciente de la Corte Suprema en la estructura del recurso de protección, al ser comprendido como recurso extraordinario. Además, se analizan los efectos de las decisiones del Tribunal Constitucional y la posibilidad de su control por vía del mencionado recurso de protección.
\end{abstract}

Palabras clave: recurso de protección, recurso extraordinario, cosa juzgada constitucional

1 Profesora de derecho procesal constitucional, Universidad de los Andes, Chile; Doctora en Derecho por la Pontificia Universidad Católica de Valparaíso, Chile; Dirección: Avenida Mon. Álvaro del Portillo, $\mathrm{N}^{\circ}{ }_{12.455}$ Las Condes, Santiago, Chile; email: pmachado@uandes.cl. Este trabajo es parte del proyecto Fondecyt Iniciación (Conicyt Chile), No 11170502, titulado "La cosa juzgada en las acciones constitucionales de protección", en la cual la autora es investigadora responsable.

Artículo recibido el 30.10.2019 y aceptado para publicación el 25.06.2020. 


\begin{abstract}
This article aims to analyze the procedural consequences that the recent jurisprudence of the Supreme Court may have on the structure of the protection remedy, as it is understood as an extraordinary remedy. In addition, the effects of the decisions of the Constitutional Court and the possibility of their control through the aforementioned protection remedy are analyzed.
\end{abstract}

Keywords: protection action, extraordinary appeal, constitutional res judicata

\title{
1. Introducción
}

El día siete de octubre de dos mil diecinueve, la Tercera Sala de la Excma. Corte Suprema dictó sentencia en los autos No 21.027-19 del ingreso de dicho Tribunal, incoados por recurso de protección deducido por la Confederación Nacional de Trabajadores Municipales de Chile, ASEMUCH y doña Marvy Navarrete Jaque, en contra del Tribunal Constitucional, por la dictación de la sentencia recaída en los antecedentes de inaplicabilidad Rol 3.853-17, que con fecha seis de diciembre de dos mil dieciocho, acogió el requerimiento formulado por la Ilustre Municipalidad de San Miguel, declarando inaplicable, en los autos № 37.905-17 del ingreso de la Corte Suprema, los artículos $1^{\circ}$ inciso tercero y 485 del Código del Trabajo.

El referido proceso $\mathrm{N}^{\mathrm{o}} 37.905-17$, corresponde a uno iniciado en sede laboral por denuncia de tutela de derechos fundamentales interpuesta por una funcionaria a contrata del mencionado ente edilicio, que fue acogida por el juez de instancia y posteriormente desestimado el recurso de nulidad que se dedujo en su contra, reclamándose la infracción de las normas que se indican. Mientras estaba pendiente el conocimiento del recurso de unificación de jurisprudencia que se dedujo, se efectuó el requerimiento de declaración de inaplicabilidad referido, cuya decisión estimatoria fue impugnada mediante el recurso de protección que dio lugar al fallo que se menciona.

Debe señalarse, que en una primera oportunidad, la Corte de Apelaciones de Santiago, declaró inadmisible la referida acción constitucional, pues mediante decisión de diez de enero de dos mil diecinueve, señaló que "de la presentación no se advierte la existencia de hechos que vulnerarían las garantías constitucionales que la presente acción cautelar protege y que señala el artículo 20 de la Constitución Política de la República, lo que impide constatar que la acción presentada reúna los requisitos que permitan declarar su admisibilidad". 
La parte recurrente apeló de tal dictamen, el que fue acogido por la Corte Suprema el veinte de febrero de ese año, ordenando darle tramitación, y en la oportunidad procesal correspondiente, fue rechazado por el tribunal pertinente, sobre la base, entre otras argumentaciones, la imposibilidad estipulada expresamente en el ordenamiento jurídico vigente, de deducir recursos en contra de los fallos del Tribunal Constitucional ${ }^{2}$.

Por su parte, el fallo en análisis, si bien confirmó la decisión denegatoria de primera instancia, lo hizo en virtud de razonamientos diversos, al eliminar el considerando tercero de dicha sentencia, por considerarlos, expresamente, como equivocados. Señala, al efecto, que la acción constitucional en referencia, corresponde a una de cautela de derechos fundamentales, cuyo fin es otorgar amparo judicial oportuno, razón por la cual, si bien no puede entenderse como un "recurso" que permita revisar lo resuelto por los tribunales ordinarios, al ser su objeto la constatación de actos u omisiones ilegales y/o arbitrarios, el recurso puede prosperar, desde que, lo que se alega, es que el órgano recurrido se excedió de sus competencias. En síntesis, la autonomía e independencia del Tribunal Constitucional no impide que "las actuaciones del órgano, llevadas a cabo al margen de las

\footnotetext{
2 Señala el motivo tercero del fallo dictado en los antecedentes No $_{566-19}$ del ingreso de la Iltma. Corte de Apelaciones de Santiago, que incide en los autos No 21.027-19 de la Corte Suprema, lo siguiente:

"Desde luego, al solicitarse que se deje sin efecto la sentencia, se desconoce el mandato contenido en el artículo 94 de la Constitución, en cuanto que contra las resoluciones del Tribunal Constitucional no procede recurso alguno. Ante tan claro precepto que en términos absolutos niega toda posibilidad de impugnación, no se divisa de qué manera pudiera prosperar un recurso, cualquiera que sea su naturaleza jurídica.

Desde otro punto de vista, es menester tener en consideración lo dispuesto por el artículo 1 de la ley 17.997, Orgánica Constitucional del Tribunal Constitucional, cuando señala que éste es un órgano del “...Estado, autónomo e independiente de otra autoridad o poder. Así entonces, cómo podrían revisarse los fundamentos de su fallo y, más todavía, dejarlo sin efecto, sin afectar gravemente su autonomía e independencia.

Otro hecho que debe tenerse en cuenta, dice relación con la naturaleza del recurso intentado. Como es sabido se trata de una acción cautelar de urgencia, llamada a disponer medidas con igual carácter, que afecten o perturben derechos constitucionales indubitados, lo que por cierto no ocurre en la especie, pues lo pretendido es que se emita un pronunciamiento sobre la materia que fue objeto del requerimiento, opinión que para el caso de ser discrepante, debiera prevalecer por sobre lo resuelto en su sentencia por el Tribunal. Ciertamente, lejos está de poder considerarse que se trate de una cuestión de carácter cautelar. Debe agregarse a lo dicho, que resolver como lo pretende el recurrente daría lugar a que, eventualmente, debiera pronunciarse como tribunal de segunda instancia la Excma. Corte Suprema, que de esta manera revisaría lo actuado por un órgano que está expresamente excluido de su superintendencia, correccional y económica, según la manda el art culo 82 de la Constitución Política.

En suma, no resulta posible por esta vía extraordinaria revisar lo actuado por un órgano que actuó en el ámbito de su competencia exclusiva cumpliendo a cabalidad el mandato contenido en los artículos 6 y 7 , de la misma Constitución, razón por la el recurso debe ser rechazado". Disponible en el portal web del poder judicial www. pjud.cl (última visita, el día 29 de octubre de 2019)
} 
atribuciones entregadas por la ley o la Constitución, pueden ser controladas por la vía jurisdiccional mediante esta acción constitucional".

En todo caso, agrega que no se acogerá el arbitrio, pues tal ejercicio debe realizarlo el juez que le corresponde decidir la gestión pendiente, lo que excluye la necesidad de cautela en sede de protección, pues son "los integrantes que concurrieron a la vista de la causa Rol CS $N^{\circ} 37.905-2017$, los que deben determinar el alcance de la sentencia del Tribunal Constitucional Rol 3853-17-INA, para efectos de resolver el recurso de unificación de jurisprudencia que se encuentra pendiente ante ellos", y que "debe verificar qué parte del pronunciamiento del Tribunal Constitucional es vinculante y obligatorio por emanar del ejercicio de las atribuciones que la Constitución y la ley le han entregado", confirmando la decisión apelada.

3 El fallo en análisis expresa, en sus fundamentos quinto al séptimo de la decisión de mayoría, lo siguiente

"Quinto: Atribuciones del Tribunal Constitucional. No existe ninguna duda respecto de la autonomía e independencia del Tribunal Constitucional, sin que pueda otro órgano del Estado inmiscuirse en las materias que la ley y la Constitución han puesto bajo la órbita de su competencia. Empero, aquello no significa que, por su calidad de órgano autónomo, todas sus actuaciones queden al margen de la revisión que pueda hacer la jurisdicción conforme a los procedimientos que la propia Carta Política contempla y de la cual no se le ha excluido en dicho ordenamiento, como tampoco en la Ley Orgánica Constitucional respectiva. Además, la autonomía del Tribunal Constitucional se vincula exclusivamente con el ejercicio de las facultades que le han sido expresamente conferidas por el ordenamiento jurídico, ergo, las actuaciones del órgano, llevadas a cabo al margen de las atribuciones entregadas por la ley o la Constitución, pueden ser controladas por la vía jurisdiccional mediante esta acción constitucional.

Ahora bien, lo expuesto no determina el acogimiento de la presente acción.

En efecto, el asunto medular acusado en el arbitrio se vincula con la acción del órgano recurrido al margen de lo establecido en los artículos $6^{\circ}$ y $7^{\circ}$ de la Carta Fundamental, en tanto se habría excedido en el ejercicio de sus facultades al declarar inaplicables el artículo $1^{\circ}$, inciso tercero y 485 de Código del Trabajo en los autos laborales ya aludidos con anterioridad. Pues bien, lo anterior lleva al análisis de lo dispuesto en el artículo $93 N^{\circ} 6$ de la Carta Fundamental, que consagra la atribución del Tribunal Constitucional para resolver, por la mayoría de sus miembros en ejercicio, la inaplicabilidad de un precepto legal cuya aplicación en cualquier gestión que se siga ante un tribunal ordinario o especial, resulte contrario a la Constitución.

La referida norma consagra la acción de inaplicabilidad por inconstitucional, cuyos presupuestos para una sentencia favorable son la existencia de una gestión judicial pendiente ante un tribunal ordinario o especial, la constatación que un precepto legal presenta una antinomia con la Constitución Política de la República y el cual corresponde aplicar en la decisión del asunto debatido en dicho procedimiento. De ello se sigue que el objeto de la referida acción es limitado, toda vez que se vincula expresamente con la existencia de preceptos que están llamados a decidir el caso concreto y que se encuentran en contradicción con la Carta Fundamental. Es por tal razón que al acogerse la acción serán declaradas inaplicables aquellas disposiciones específicas y exclusivamente en la gestión pendiente que motivó el pronunciamiento.

Sexto: Recapitulación: Objeto del recurso. El recurrente pretende que esta Corte analice y resuelva si el Tribunal Constitucional, al dictar la sentencia de seis de diciembre de dos mil dieciocho en los autos rol $N^{\circ} 3853-17$ INA actuó fuera del marco de su competencia, cuestión que implica determinar si tal órgano puede declarar inconstitucional la interpretación de una norma legal y no el precepto mismo, sobre la base de la transgresión del principio de juridicidad que el mismo ente desarrolla. Es decir, se requiere que a través de la presente vía cautelar se determine si el tribunal se limitó a establecer la constitucionalidad del precepto o, excediendo las 
Como se observa, no obstante desestimar el recurso de protección, el fallo en análisis reconoce la posibilidad de revisar las decisiones del Tribunal Constitucional por dicha vía, dándole en la práctica -aunque lo niegue expresamente-, la operatividad propia de un recurso. Si bien se suaviza tal conclusión indicando que se trata de un control que se enfoca en la sujeción a los márgenes legales y constitucionales de sus atribuciones, en el fondo está declarando que la acción del artículo 20 de la Carta Fundamental, puede dirigirse en contra de decisiones del Tribunal Constitucional, para justamente, revisar su constitucionalidad en el ejercicio de sus atribuciones.

Ello implica, que la mayoría de los ministros integrantes, consideraron que eventualmente, podrían, acogiendo el recurso de protección, declarar conculcatoria de alguna garantía constitucional y, consecuencialmente, dejar sin efecto, una sentencia emanada del órgano referido, cuestión propia de los medios recursivos jurisdiccionales.

En tal contexto, es que se considera que el fallo de la Corte Suprema, de alguna manera propone un rediseño del ámbito de aplicación del recurso de protección, que merece un análisis crítico, que es el objeto de las siguientes líneas.

No se debe olvidar que doctrinalmente, la "protección" que regula el artículo 20 de la Constitución Política de la República, corresponde a una acción de

atribuciones entregadas en el artículo $93 N^{\circ} 6$ de la Carta Fundamental, declara inconstitucional la interpretación que ha sido efectuada por los tribunales de justicia, con lo cual se inmiscuiría en una labor propia de los tribunales ordinarios.

Séptimo: Ámbito del recurso de protección y competencia de los jueces del fondo. El examen propuesto por el actor no puede ser efectuado en esta sede cautelar, pues aquello debe ser objeto del análisis del juez que debe resolver la gestión pendiente, toda vez que es en tal sede en la que se debe verificar qué parte del pronunciamiento del Tribunal Constitucional es vinculante y obligatorio por emanar del ejercicio de las atribuciones que la Constitución y la ley le han entregado y, en consecuencia, es el juez de la causa, en el caso concreto, los integrantes que concurrieron a la vista de la causa Rol CS $N^{\circ}$ 37.905-2017, los que deben determinar el alcance de la sentencia del Tribunal Constitucional Rol 3853-17-INA, para efectos de resolver el recurso de unificación de jurisprudencia que se encuentra pendiente ante ellos. Es por ello que, al estar radicado el conocimiento de los antecedentes ante el tribunal competente, excluye la necesidad de cautela urgente, cuestión que determina que no se cumplan las exigencias previstas para la procedencia del presente recurso de protección.

Además, se debe precisar que los actores han solicitado no sólo la constatación y declaración de ilegalidad de la actuación del Tribunal Constitucional sino que se requiere se ordene que, en lo sucesivo, se abstenga de emitir pronunciamientos que determinen la inaplicabilidad del procedimiento de tutela de derechos fundamentales previsto en el artículo 485 del Código de Trabajo a empleados públicos. Tal declaración no puede ser realizada, no sólo por lo reseñado en los fundamentos precedentes, sino porque, además, no puede esta Corte señalar al Tribunal Constitucional, órgano autónomo, cómo debe ejercer sus facultades, sin que, por lo demás, deba recordarle que en el ejercicio de aquellas debe respetar la Constitución y la ley". Disponible en el sitio web del poder judicial, www.pjud.cl (última revisión, 29 de octubre de 2019). 
naturaleza sumarísima que tiene por objeto concreto, la tutela de las garantías constitucionales de los ciudadanos, por cuanto fue diseñada para resguardar los derechos fundamentales preexistentes e indubitados en contra de acciones arbitrarias o ilegales practicadas por funcionarios públicos o particulares.

Esta acción constitucional, cuya regulación, a mucho debió haber sido objeto de ley, está establecida por un Auto Acordado de la Corte Suprema, modificado en 27 de septiembre de 2018 , y es considerada como una acción de urgencia, pues se trata de un procedimiento rápido e informal.

En la práctica jurisprudencial, en concordancia con lo anteriormente dicho, si el derecho cuyo amparo se reclama, carece de liquidez o certeza, el recurso se desestima por no fundarse en un derecho indubitado, lo mismo sucedía en el caso que la situación planteada se encontrara sometida al conocimiento jurisdiccional de otro tribunal, o recurso, evento en que el rechazo, como sucedió en la especie, se verifica por encontrarse discutido bajo el amparo de los tribunales de justicia. $\mathrm{Y}$, consistente con lo anterior, también eran desestimadas las acciones impetradas en contra de decisiones jurisdiccionales, salvo en el caso que se intente hacer valer su fuerza vinculante a terceros o sujetos que no fueron emplazados en el proceso pertinente.

No obstante lo anterior, la Corte Suprema en la sentencia de siete de octubre de dos mil diecinueve ya referido, dio un giro jurisprudencial admitiendo el recurso de protección en contra de sentencias para cuestionar la constitucionalidad de las sentencias del propio Tribunal Constitucional ${ }^{4}$.

Entendemos que tal desplazamiento jurisprudencial le otorga al recurso de protección un diseño técnico procesal que durante muchos años la doctrina y los tribunales le negaron expresamente ${ }^{5}$, esto es, de considerar dicha herramienta constitucional como un recurso en sentido propio, y que en este caso, específica-

\footnotetext{
$4 \mathrm{Si}$ bien es cierto que la jurisprudencia permitía, en casos bien excepcionales a terceros que no pudieron participar del juicio y fueron alcanzados por la sentencia, la interposición de recurso de protección en contra de resoluciones judiciales, también encontramos el trabajo de Ried (2015) indicando que sería posible plantear la posibilidad de la interposición de recursos de protección para controlar la constitucionalidad de las sentencias judiciales civiles. No obstante, lo que aquí defendemos es exactamente una posición contraria.

5 "El recurso de protección fue mal diseñado, puesto que al día de hoy no ha logrado clarificar si es un sustituto de la jurisdicción común o es derechamente una acción constitucional para la tutela de derechos fundamentales". En: Bordalí (2011), p. 66; "El denominado recurso de protección no circunscribe el ámbito de su aplicación a las resoluciones judiciales, sino que cubre toda la gama de decisiones públicas, con ciertas excepciones importantes" en NogueIra (1999), p. 160.
} 
mente, a pesar del intento, a nuestro juicio infructuoso, de reafirmar la exclusión de su carácter recursivo, en la práctica lo reviste con el carácter de recurso extraordinario, esto es, no como una categoría recursiva, sino como aquel específico medio de impugnación, propio del derecho comparado, específicamente en el ordenamiento procesal brasileño, destinado específicamente, entre otros fines, a impedir las conculcaciones a la Constitución, modelo que en su momento, fue considerado a propósito de la gestación del proyecto de código procesal civil chileno.

A objeto de examinar estos nuevos márgenes, creemos que es menester referirse la naturaleza del recurso de protección, y revisar como este diseño jurisprudencial de recurso extraordinario, en los términos señalados, puede impactar en lo que conocemos como esencia de dicha acción, en especial, en lo relativo a su relación con la cosa juzgada constitucional, y su incidencia en contra de las decisiones de inaplicabilidad dictadas por el Tribunal Constitucional.

De esta manera, se plantea como cuestionamiento a revisar, si es viable considerar al recurso de protección como un recurso constitucional extraordinario y su posibilidad de interponerlo en contra de las decisiones del Tribunal Constitucional, atendida las peculiares características procesales de la acción constitucional referida, y en la dificultad que implica considerar permitido el control de las decisiones del Tribunal Constitucional por esta vía. No obstante, no es intención del presente trabajo el estudio del recurso extraordinario en específico, sino que negar esta categoría al recurso de protección.

\section{El recurso de protección como recurso extraordinario: problemas de su implementación}

El recurso extraordinario, como se expresó anteriormente, corresponde a un medio de impugnación especial que tiene por finalidad la protección de la constitucionalidad de las decisiones judiciales, que en el derecho comparado, específicamente en el modelo procesal brasileño se define como un instrumento jurídico procesal-constitucional destinado a asegurar la verificación de una eventual afrenta a la Constitución, debido a la decisión dada en última o única instancia por el Poder Judicial, conforme lo define el artículo 102, inciso III de la Constitución brasileña ${ }^{6}$.

6 Art. 102. Compete ao Supremo Tribunal Federal, precipuamente, a guarda da Constituição, cabendo-lhe: [...] III. julgar, mediante recurso extraordinário, as causas decididas em única ou última instância, quando a 
En Brasil, hasta la entrada en vigencia de la Constitución de 1988, el recurso extraordinario era el más importante mecanismo de control de constitucionalidad, sujeto a la competencia del Supremo Tribunal Federal. Este recurso excepcional, inspirado en el modelo del writ of error norteamericano ${ }^{7}$, fue introducido en el orden constitucional brasileño, mediante la Constitución de 1891, específicamente en su artículo 59, párrafo $1^{\circ}$, que determinaba que podía ser interpuesto por la parte vencida, en caso de ofensa directa a la Constitución, tratado o ley federal.

En el ámbito de la reforma del Poder Judicial brasileño, implementado por la Enmienda Constitucional 45 de 2004, el artículo 102 fue modificado a fin de incorporar en la estructura procesal del recurso el instituto de la repercusión general, que incluye para su procedencia, la exigencia a la parte recurrente de demostrar la "repercusión general" de las cuestiones constitucionales propuestas en el caso, en los términos de la ley, a fin de que el tribunal examine su admisibilidad, pudiendo rechazarla por la manifestación de dos tercios de sus miembros.

El Proyecto de Nuevo Código Procesal Civil chileno recurrió a este modelo recursivo en su artículo 405 y siguientes, estableciendo especialmente en su artículo 409, bajo el título "interés general", el literal a) que dispone expresamente: "Cuando se hubiere infringido en forma esencial, en la sentencia o en el procedimiento del cual ella emanare, un derecho o garantía fundamental contemplado en la Constitución Política de la República o en los tratados internacionales ratificados por Chile y que se encuentren vigentes".

Si bien, sus contornos difieren en cierta medida del recurso brasileño, es claro que el modelo utilizado tiene su inspiración en dicho ordenamiento jurídico. En el Mensaje 432-359 que conduce el Proyecto de Nuevo Código Procesal Civil ${ }^{8}$, se destaca que uno de los objetivos y principal aspecto de la reforma es el nuevo sistema recursivo y el rol de la Corte Suprema. Establece un rol especial y nuevo de la Corte Suprema a "preservar los derechos fundamentales y de dar coherencia y unidad a los criterios de decisión de los tribunales del país".

decisão recorrida: a) contrariar dispositivo desta Constituição; b) declarar a inconstitucionalidade de tratado ou lei federal; c) julgar válida lei ou ato de governo local contestado em face desta Constituição; d) julgar válida lei local contestada em face de lei federal.

$7 \mathrm{El}$ writ of error es un orden judicial que emana de una Corte de Apelaciones, exigiendo que un tribunal inferior transmita el expediente de un caso a la Corte de Apelaciones para que el expediente pueda ser revisado por presuntos errores de derecho cometidos durante el juicio. Cfr. Worcester v. Georgia, 31 U.S.515 (1832).

8 Mensaje No 432-359, de 27 de diciembre de 2011, del Proyecto de Código Procesal Civil.

9 Delgado Castro (2012), p. 129. 
El recurso extraordinario también comparte las características propias del denominado writ of certiorari, cuyos orígenes se remontan a una antigua expresión del common law que significaba "aportar la documentación" ${ }^{\circ}$. Dicho instrumento procesal tiene origen, a su vez, en el Judiciary Act de 1891, pero no se convirtió en el medio más utilizado de acceso a la Corte Suprema de los Estados Unidos hasta la promulgación del Judiciary Act de 1925.

Según el artículo 3 de la Constitución norteamericana, la Corte Suprema es la última instancia con dos tipos de competencias: i) como tribunal de primera instancia, o sea, como original jurisdiction, y; ii) como tribunal de apelación, o también, appellate jurisdiction. Las funciones como tribunal de apelación a su vez son dos: i) la por vía obligatoria o mandatory, y; ii) la apelación discrecional, o la discretionary, también conocida como certiorari jurisdiction. La apelación obligatoria solamente tiene lugar en los casos extraordinarios previamente establecidos en la legislación federal.

Por otro lado, el recurso discrecional del certiorari ante la Corte Suprema americana está establecido en el capítulo 81 del Código Federal de los Estados Unidos, bajo el título de procesos judiciales, en los epígrafes 1254 a 1257, donde se establece la competencia de la Corte Suprema para revisar sentencias dictadas por Cortes de Apelaciones federales y por tribunales estatales de instancia superior. En este sentido, el certiorari "es un recurso devolutivo y de carácter extraordinario, cuya finalidad es resolver cuestiones de derecho y no cuestiones fácticas, pues raramente se discute sobre errores de hecho. Los motivos que se articulan en el recurso son infracciones de normas sustantivas, aunque es posible hacer valer en el recurso infracciones de normas procesales cuando la infracción presenta implicaciones constitucionales o vulneración de normas federales"1.

En la sentencia Rol 21.027-2019, de siete de octubre de dos mil diecinueve, la Corte Suprema entendió que, como ya se transcribió, la autonomía del Tribunal Constitucional "no significa que, por su calidad de órgano autónomo, todas sus actuaciones queden al margen de la revisión que pueda hacer la jurisdicción conforme a los procedimientos que la propia Carta Política contempla y de la cual no se le ha excluido en dicho ordenamiento, como tampoco en la Ley Orgánica Constitucional respectiva. Además, la autonomía del Tribunal Constitucional se vincula exclusivamente con el ejercicio de las facultades que le han sido expresa-

10 Hazard y Taruffo (2006), p. 207; Cfr. Gilsanz Usunaga (2016), p. 126. 11 Gilsanz Usunaga (2016), p. 127; Cfr. Goodnow (1891), p. 503. 
mente conferidas por el ordenamiento jurídico, ergo, las actuaciones del órgano, llevadas a cabo al margen de las atribuciones entregadas por la ley o la Constitución, pueden ser controladas por la vía jurisdiccional mediante esta acción constitucional" ${ }^{12}$.

De este modo es evidente, a nuestro parecer, que al considerar que las sentencias del Tribunal Constitucional son susceptibles de revisión por vía de recurso de protección -aunque en algunos párrafos atrás, el fallo haya manifestado que tal instrumento carece de la naturaleza de recurso-, la Corte Suprema termina por desvirtuar la naturaleza procesal de la acción constitucional sostenida históricamente por la doctrina y dicho tribunal, haciéndola devenir en un verdadero recurso constitucional extraordinario, en los términos antes expuestos.

Dicha alteración de los márgenes del recurso de protección es una consecuencia lógica de las declaraciones formuladas por el fallo en comento, distorsionando los márgenes y contornos de la naturaleza procesal de dicho instrumento, lo que es incorrecto desde una perspectiva dogmática, lo que se intentará demostrar a continuación.

Básicamente se sostiene la falta de aptitud del recurso de protección para funcionar como un verdadero recurso, en el sentido estricto del término; y, por otro, la imposibilidad de interponer recursos en contra de las decisiones del Tribunal Constitucional, atendida la concurrencia de norma expresa que lo impide, que se concretan en varios aspectos o argumentos para desestimar la pretensión de control que emana del fallo analizado, como lo son, por un lado, la imposibilidad formal de crear recursos por vía jurisprudencial; por otro, el hecho de que la Corte Suprema carece de la asignación de competencia para controlar las decisiones del Tribunal Constitucional; además, dicha conclusión contraría y desperfila la relación de coordinación institucional que existe entre los instrumentos procesales de protección y supremacía de la Constitución en Chile; y, finalmente, el atributo de la cosa juzgada que recubre a las sentencias del Tribunal Constitucional, que impiden modificar lo fallado.

12 La Corte Suprema niega en la sentencia mencionada que el recurso de protección funcione en este caso como recurso, pero al permitir que las decisiones del Tribunal Constitucional puedan ser revisadas vía recurso de protección, termina por aceptar lo que trata de negar, esto es una posibilidad de control recursivo de las sentencias de dicho tribunal. 


\subsubsection{Respecto la imposibilidad de la creación de un recurso constitucional extraordinario por vía jurisprudencial}

Primeramente, debe señalarse que los sistemas procesales obedecen a un fundamento propio del Estado de Derecho, que es el principio de la legalidad, el cual se relaciona con los sistemas procesales desde la Magna Charta Libertatum promulgada en contra del rey Juan Sin Tierra. En su artículo 39, establece que "ningún hombre libre será arrestado, o detenido en prisión, o desposeído de sus bienes, proscrito o desterrado, o molestado de alguna manera; y no dispondremos sobre él, ni lo pondremos en prisión, sino por el juicio legal de sus pares, o por ley del país"'13.

Actualmente, el principio de la legalidad se vincula con el principio del formalismo de los actos procesales y de la seguridad jurídica de los jurisdiccionados. Principio que tiene un aspecto político y otro jurídico. Desde la perspectiva política, el principio de la legalidad es una garantía a los ciudadanos en cuanto salvaguarda el derecho que tienen los individuos para practicar cualquier conducta que no sea tipificada como ilícito. Desde el ámbito procesal, es la garantía de que será respetado el debido proceso legal. Por otro lado, y desde el aspecto jurídico, el principio de legalidad constituye un derecho de las partes y además, constituye una garantía de aplicación de justicia formal ${ }^{14}$.

El sistema recursivo, además de ser un derecho inherente y garantía de las partes, debe especialmente estar establecido en ley ${ }^{15}$. Es así que dispone el artículo 63, n. 3 de la Constitución Política, que consagra que "Sólo son materias de ley: [...] 3) Las que son objeto de codificación, sea civil, comercial, procesal, penal u otra;”.

13 "A esta cláusula debe su fama la Magna Carta. Aunque no crea el procedimiento de "habeas corpus", como a veces se afirma. Lo que este texto consagra es la doble garantía del "iudicium parium suorum" y de la "lex terrae". Lo primero significa el juicio por jurados y excluía que nadie pudiera ser condenado por un tribunal o una comisión especial dependiente del Rey. La segunda exigencia, alternativa o complementaria de la anterior (según se interpretara la conjunción disyuntiva que las enlaza en el texto) consiste en que el juicio se haga "conforme a las leyes del país". Se trata sin duda de un requisito ambiguo, que llegó a ser entendido a veces como equivalente al primero (a fin de cuentas, las leyes del país, esto es el Common Law, exigían el juicio por jurados desde el siglo XII). Sin embargo, a la postre, prevaleció una interpretación de la "lex terrae" como una garantía de contenido más amplio, como el derecho al debido proceso legal ("due process of law"), es decir, el derecho a la legalidad procesal en todos sus aspectos o el derecho a un juicio justo". En: SATrúsTEGUI Gil-Delgado (2009), pp. 250-251.

14 Cfr. NúÑez OJeda (2008), p. 202.

15 "La existencia de todo recurso debe ser contemplada por parte del legislador, por cuanto ello implica reconocerle atribuciones a los tribunales para conocer de él, resolviendo los asuntos que la ley ha entregado a su conocimiento". En Mosquera Ruiz y Maturana Miquel (2010), p. 22. 
Esto quiere decir que solamente una ley puede crear recursos, siendo prohibida a cualquier otra esfera de poder, sea ejecutiva o jurisdiccional concebir y establecer figuras recursivas ${ }^{16}$. Esto es así, pues los recursos obedecen a un principio de taxatividad legal, conforme enseña Luiz Guilherme Marinoni, Daniel Mitidiero y Sergio Arenhart ${ }^{17}$.

En este sentido, el recurso de protección, para ser comprendido como medio de impugnación de decisiones judiciales, presenta dos óbices: i) no fue establecido por la ley; ii) no es un mecanismo propio para impugnar sentencias, sino actos.

En efecto, en relación al primer punto, debe recordarse, que el recurso de protección fue establecido - en su configuración vigente - por medio de Auto Acordado de la Corte Suprema 94-2015 y no por ley, como exige la Constitución Política y la definición que da el artículo 20 de la Carta Magna y el referido Auto Acordado es de que el recurso de protección tiene la finalidad de la impugnación de actos y no la impugnación de sentencias, lo que lo transforma en verdadera acción jurisdiccional y no en recurso.

Otro principio propio de los sistemas recursivos es el principio jerárquico, que se aplica preferentemente para determinar el tribunal competente para conocer de un recurso. Conforme este regla, el recurso interpuesto siempre lo debe conocer y fallar el superior jerárquico del tribunal que pronunció la resolución que se impugna ${ }^{18}$. En el caso sub análisis, las Cortes de Apelaciones y la Corte Suprema no son Tribunales jerárquicamente superiores al Tribunal Constitucional, y, además, sus competencias no están vinculadas directamente, conforme veremos más adelante.

Por otro lado, los recursos obedecen a otro principio relevante, este es, el de la unirrecurribilidad, pues, dado que es la ley procesal la que estipula cuáles son los recursos posibles, la ley debe indicar que para cada especie de acto jurisdiccional a ser recurrido, debe ser oponible un único recurso. Es cierto que en varios casos la ley permite la interposición de más de una especie de recurso en contra de la misma resolución judicial, pero, no se puede olvidar, que cada uno de ellos tiene

16 Importante destacar que en el derecho español se discute si el amparo constitucional funciona con una lógica propia del recurso de casación. Manuel Aragón defiende esa posición, ya que ve en el Tribunal Constitucional al máximo intérprete de los derechos fundamentales, con facultades para casar y revisar las sentencias de la jurisdicción ordinaria, en un diseño muy distinto al recurso de protección. Cfr. ARAGón (2004), pp. 148 y ss; Cfr. Bordalí (2006), nota 57.

17 MARINONi et alii (2015), pp. 510 y ss.

18 Mosquera Ruiz y Maturana Miquel (2010), pp. 52-53. 
una función específica, que no se confunde con la finalidad prevista para la otra especie de recurso. De este modo, contra determinado acto jurisdiccional y para cierta finalidad específica, debe ser oponible un solo recurso.

Además, crear jurisprudencialmente un recurso constitucional extraordinario por vía jurisprudencial, aprovechando la decisión en un recurso de protección también afecta el sistema de legitimidad recursiva.

Pues bien, como regla general, las partes son las únicas legitimadas a impugnar una determinada resolución jurisdiccional ${ }^{19}$, es decir, deben ser las partes -aquéllas que serán afectadas por el resultado del proceso-, las indicadas a solicitar su revisión ante un tribunal superior ${ }^{20}$.

Sin embargo, en el caso de que sea posible un recurso de protección en contra de cualquier sentencia y también de las sentencias del Tribunal Constitucional, el artículo $2^{\circ}$ del Auto Acordado 94-2015 entraría en conflicto con la teoría de la legitimación recursiva, dado que dispone que "el recurso se interpondrá por el afectado o por cualquiera otra persona en su nombre, capaz de parecer en juicio, aunque no tenga para ello mandato especial, por escrito en papel simple o por cualquier medio electrónico". En dicho caso, cualquier persona que no es parte, incluso sin mandato especial, podría impugnar una sentencia, sin cumplir con el requisito propio de los recursos que es la existencia del agravio.

El principio de la preclusión de los recursos también estaría restringido en el caso de que sea posible la interposición de recurso de protección como recurso constitucional extraordinario, una vez que el Auto Acordado 94-2015 dispone en su artículo $1^{\circ}$, que "dentro del plazo fatal de treinta días corridos contados desde la ejecución del acto o la ocurrencia de la omisión o, según la naturaleza de éstos, desde que se haya tenido noticias o conocimiento cierto de los mismos, lo que se hará constar en autos". Los recursos procesales tienen una oportunidad o plazo fatal, dentro del cual las partes pueden impugnar una determinada resolución jurisdiccional. Este plazo tiene su término inicial cuando la parte es regularmente notificada. Dicho principio tiene especial relevancia en la duración razonable del proceso y en el principio dispositivo ${ }^{21}$.

19 Cadiet y Jeuland (2017), p. 678.

20 Dal punto di vista soggettivo occorre distinguere i mezzi di impugnazione proponibili dalla parti dai mezzi di impugnazione proponibii dai terzi. Per parte si intende colui che ha assunto, nella fase che ha portato allemanazione della sentenza che si impugna, la qualità di parte in senso processuale (nel senso di colui a cui sono imputati gli effetti ddegli atti processuali). En Luiso (2013), p. 304.

21 GANDUlFo R. (2009), p. 148. 
Dado que el recurso de protección permite a terceros el ejercicio de dicha acción en su nombre y sin mandato especial, el plazo de 30 días estaría matizado al momento de que este tercero tomó conocimiento del contenido de la resolución y no a partir de la notificación. En relación a la legitimación, esta estaría restringida en un sistema recursivo a las partes alcanzadas por la sentencia.

Last but not least, el recurso de protección no posee los efectos propios de los recursos procesales, o sea, efecto devolutivo, suspensivo, traslativo, expansivo y sustitutivo. El recurso de protección por su naturaleza de acción, no posee el efecto devolutivo. Dicho efecto se refiere a la posibilidad de cognición del tribunal ad quem para las cuestiones impugnadas por la parte y por las cuestiones que la ley, independientemente de impugnación, permite al órgano jurisdiccional conocer por fuerza de la interposición del recurso ${ }^{22}$. Marinoni, Mitidiero y Arenhart enseñan que las primeras cuestiones son devueltas al órgano recursivo, al paso que las segundas son trasladadas (efecto traslativo) ${ }^{23}$. La unión de ambas cuestiones compone el cuadro de la materia que puede ser conocida por el tribunal ad quem. El efecto devolutivo tiene relación con la regla de grado, prevista en el artículo 110 del Código Orgánico de los Tribunales que expresa "una vez fijada con arreglo a la ley la competencia de un juez inferior para conocer en primera instancia de un determinado asunto, queda igualmente fijada la del tribunal superior que debe conocer del mismo asunto en segunda instancia”, pero sobre la competencia analizaremos detenidamente en el punto siguiente.

El efecto suspensivo también no es un efecto propio del recurso de protección y ni está previsto en él, solamente siendo admitida la orden de no innovar, a solicitud de parte ${ }^{24}$. Por fin el efecto sustitutivo los recursos, que indica que una vez conocido un recurso, la decisión del juicio ad quem, cualquier que sea su contenido, sustituirá la decisión recurrida ${ }^{25}$. El efecto sustitutivo está expresado en el artículo 170 del Código de Procedimiento Civil, en su inciso final cuando dice que "Si la sentencia de primera instancia reúne estos requisitos, la de segunda que mo-

22 "La dévolution limitée, ou partielle, du litige est la première conséquence de la règle. Il ne faut cependant pas méprendre sur sa signification. D’une part, il ne peut être dévolu à la cour plus qu'il n’a été jugé au premier degré: tantum devolutum, quantum judicatum; ainsi l'impose le príncipe du doublé degré de juridiction. D’autre part, il n'est dévolu qu'autant qu'il est appelé: tantum devolutum, quantum appelatum, ce qui est la traduction au second degré de jurisdiction du príncipe dispositif”. En CADIET y Jeuland (2017), p. 702.

23 MARinoni et alii (2015), p. 524 y ss.

24 Luiso (2013), p. 407.

25 "La sentenza del giudice d'apello è sostitutiva a tutti gli effetti di quella di primo grado, anche se conferma in tutto e per tutto la pronuncia impugnata". Luiso (2013), p. 413. 
difique o revoque no necesita consignar la exposición de las circunstancias mencionadas en los números $1^{\circ}, 2^{\circ}$ y $3^{\circ}$ del presente artículo y bastará referirse a ella”.

De este modo, a nuestro ver el recurso de protección no podría de ningún modo ser concebido como recurso constitucional extraordinario. Nuestra posición es contraria a la defendida por Ignacio Ried Undurraga, cuando afirma "Lo que propongo en este trabajo, a la luz de la jurisprudencia que se analiza en el capítulo siguiente, es abrir la posibilidad de que nuestras Cortes de Apelaciones, y en definitiva, la Corte Suprema, revisen la constitucionalidad de las sentencias judiciales civiles, y dejen sin efecto aquéllas en que se han vulnerado en forma grave y notoria las garantías fundamentales de alguna persona. Es este el sentido y alcance que le han dado algunos fallos que han acogido acciones de protección. No es abrir una puerta a una tercera o cuarta instancia, sino simplemente establecer un "dique mínimo" que sirva de freno para ciertas arbitrariedades especialmente graves que pueden cometerse en el proceso civil" ${ }^{26}$.

No negamos que jurisprudencialmente se ha admitido recurso de protección respecto "de aquellas resoluciones judiciales que causan agravio o lesión a los derechos fundamentales de terceros que no son parte en el proceso en que ellas - las resoluciones - se dictaron, de modo que a raíz de ello, el afectado o lesionado no ha sido oído al dictarse la resolución ni tampoco ha podido ejercer los medios de defensa de sus derechos. En estas circunstancias, las Cortes con bastante continuidad han aceptado tramitar y en definitiva han acogido recursos de protección" ${ }^{27}$. No obstante, esta posibilidad es aquella que garantiza a un tercero que no tiene la posibilidad de presentar ningún otro tipo de recurso procesal para alejar los efectos de una decisión de la cual no ha participado y su aplicación es extraordinaria, no siendo comparable con la apertura que la sentencia en el Rol No 21.027-2019 ha generado. En efecto, en dichos casos, la sentencia no tiene tal calidad para aquellos que no han sido emplazados, o por lo menos, no los vincula, conforme dispone el inciso segundo del artículo tercero del Código Civil, de manera que para dichos recurrentes, el fallo que se impugna, no pasa de ser un acto que indebidamente los vincula.

26 Ried UnduRraga (2015), p. 296.

27 Gómez (2008), pp. 26 y 27. 


\subsubsection{Respecto de la ausencia de competencia de la Corte Suprema para revisar sentencias del Tribunal Constitucional}

Lamentablemente, el sistema de control de constitucionalidad vía tribunal especial como el Tribunal Constitucional, es nuevo en la historia de Chile ${ }^{28}$. Además, el sistema tal como lo conocemos fue modificado solamente en el año 2005, por reforma constitucional. Cierto es, también, que el sistema normativo de articulación entre la Corte Suprema o el Poder Judicial y el Tribunal Constitucional, es deficitario. No obstante, es posible separar los ámbitos de competencia de cada uno de ellos y determinar su punto de encuentro.

La competencia, según Francesco P. Luiso, puede ser definida como la repartición interna del poder perteneciente a cualquier ámbito jurisdiccional (jurisdicción administrativa, constitucional, ordinaria, especial, etc.) ${ }^{29}$. Se dice que la competencia es funcional cuando la ley la determina en razón de la función a ser ejercida por un determinado órgano el ejercicio del poder jurisdiccional. Esta división del poder jurisdiccional en razón de su función puede ser de dos tipos: horizontal y vertical. Desde su aspecto horizontal, la competencia se determina entre tribunales del mismo plano y la competencia desde su aspecto vertical, se determina entre jueces de grados de jurisdicción diversos ${ }^{30}$.

El Tribunal Constitucional no se encuentra vinculado en su competencia al Poder Judicial por vía de competencia en su aspecto vertical, pues ni el Tribunal Constitucional hace parte de los grados del ejercicio jurisdiccional del Poder Judicial, como tampoco los tribunales pertenecientes al Poder Judicial conforman a su vez grados de jurisdicción en la Justicia Constitucional. Su competencia es, en este sentido, verticalmente independiente y autónoma.

Desde el ámbito horizontal, determinado en razón de la materia, debemos hacer algunos matices. Primeramente, todos los tribunales e instituciones públicas y privadas de la República son responsables de preservar y ejecutar el texto constitucional, conforme determina el artículo $6^{\circ}$ de la Constitución de la República:

28 Dado que la previsión de control de constitucionalidad por vía inaplicabilidad en la Constitución política de 1925 establecía la Corte Suprema como órgano competente y no el Tribunal Constitucional. El Tribunal Constitucional, creado en 1970, y cerrado en 1973, solamente volvió a funcionar con la Constitución de 1980. Cfr. Pardow Lorenzo y Verdugo Ramírez (2015), pp.127-131; Cfr. Nogueira Alcalá (2003), p. 59-131.

29 Luiso (2017), p. 90.

30 La doctrina francesa denomina como compétence d'attribution, la competencia en razón de la función que ejercen los diversos tribunales en un determinado sistema procesal. En: Couchez (1998), p. 19 y ss. 
"Los órganos del Estado deben someter su acción a la Constitución y a las normas dictadas conforme a ella, y garantizar el orden institucional de la República. Los preceptos de esta Constitución obligan tanto a los titulares o integrantes de dichos órganos como a toda persona, institución o grupo. La infracción de esta norma generará las responsabilidades y sanciones que determine la ley”. Sin embargo, conforme analizaremos más abajo, cada uno de los diferentes instrumentos procesales establecidos en nuestro ordenamiento jurídico tiene por objeto cumplir con este mandato constitucional. Es por esto que la competencia horizontal en razón de la materia, es decir, la constitucional, corresponde a todo tribunal, empero la tramitación de determinados institutos procesales solamente son de competencia de un tribunal en detrimento de otro.

De esta suerte, podemos afirmar que si bien es cierto que tanto el Poder Judicial como el Tribunal Constitucional tienen el deber de protección y mantención de los preceptos constitucionales, también es cierto que determinadas acciones deben ser tramitadas por la jurisdicción constitucional y otras por la jurisdicción ordinaria. Nuestro sistema ha atribuido al Tribunal Constitucional la competencia del control de constitucionalidad in abstracto y como también in concreto, o sea, la acción de inconstitucionalidad y la acción de inaplicabilidad, respectivamente.

Por otro lado, como sabemos, el legislador ha dejado en la competencia de los tribunales ordinarios, la tramitación de las acciones que tutelan las libertades, o sea, el recurso de protección, el recurso de amparo, la tutela laboral y la acción de no discriminación arbitraria.

Esta separación de competencia entre ambas jurisdicciones -una especial y otra ordinaria- , tiene razón lógica. En primer lugar, el constituyente ha optado por un sistema concentrado de control de constitucionalidad y no un sistema difuso $^{31}$. En los sistemas difusos, todo y cualquier juez tiene la competencia para declarar la inconstitucionalidad de preceptos legales o interpretaciones de la ley.

31 Los jueces a quo también lo son por deber legal, una vez que la interpretación de las leyes no puede ir en contra de la Constitución. La interpretación legal, en efecto, debe ser realizada en conformidad con la Constitución. Además, el juez tiene la obligación de procurar otorgar la aplicación más constitucional posible de la ley, conforme lo previsto en el artículo $6^{\circ}$ de la Constitución Política de la República. Sin embargo, esto no es control de constitucionalidad de la ley. La decisión proferida en el juicio a quo no pueden dar los efectos que las decisiones del Tribunal Constitucional dan. Los jueces ordinarios no pueden hacer el calibramiento del ordenamiento jurídico por medio de la expulsión de normas inconstitucionales. Por último, su decisión es susceptible de recursos, donde la interpretación puede ser revisada por un tribunal superior, lo que no sucede con las sentencias proferidas por el Tribunal Constuticional. En Machado Martins (2017), p. 178. 
En nuestro sistema esto no es posible ${ }^{32}$. Solamente por la opción de modelo de jurisdicción constitucional, sería imposible a la Corte Suprema controlar la interpretación realizada por el Tribunal Constitucional en sus resoluciones.

En la sentencia del Rol 21.027-2019, la Corte Suprema fundamenta su decisión aseverando que el "artículo 94 de la Carta Fundamental no impide que la presente acción pueda prosperar, toda vez que la acción de protección no puede ser entendida como un recurso cuyo objeto sea enmendar lo resuelto por el Tribunal Constitucional, sino que propiamente, conforme a su naturaleza, es una acción constitucional cuyo objeto preciso es determinar si la actuación impugnada incurrió en una vulneración de la Constitución y la ley, en el caso de autos, al señalar los actores que el órgano constitucional excedió al ámbito de sus competencias". El Tribunal Constitucional no adjudica derechos a las partes, sino que decide la compatibilidad de normas e interpretaciones legales de forma a proteger la constitucionalidad de la aplicación de la ley. Su actuar está dirigido al juez y no a las partes $^{33}$.

La Corte Suprema ya tiene un mecanismo de control de infracción a la Constitución por vía del recurso de casación en el fondo, el cual opera sobre la base del fin nomofiláctico que le corresponde, mediante el control de la correcta interpretación de la ley decisoria litis. Es pacifico en la doctrina que el alcance que se le da a la expresión ley, incluye a las normas constitucionales, cuya vulneración, en la medida que se trate del precepto sustantivo que determinó la decisión impugnada, puede y debe ser controlado por la Corte Suprema. Dicha facultad no interfiere con aquellas que le competen al Tribunal Constitucional, por cuanto existe una coordinación institucional entre los fines del recurso de casación sustantivo y el de inaplicabilidad. Así lo plantea la doctrina al señalar que "si existiere una sentencia que se dicte desconociendo esta normativa constitucional, lo que cabe es recurrir ante los tribunales y no acudir al requerimiento de inaplicabilidad, dado lo que se solicita es enmendar el error de derecho contenido en una sentencia, materia sobre la cual carece de facultades el Tribunal Constitucional, al no

32 Si bien es cierto que Garrote Campillay (2012) entiende que el sistema constitucional chileno es un sistema de control de constitucionalidad difuso, la verdad es que ni la Constitución ni la ley han establecido tal mecanismo, estableciendo al contrario, un sistema concentrado en todos sus sentidos. Cfr. MACHADO MaRTins (2017), p. 188.

33 "En efecto, el principal interés tutelado en el control de constitucionalidad incidental es aquello general y objetivo de la constitucionalidad de la ley cuestionada y no la controversia a quo, pues la parte busca la correcta aplicación del derecho objetivo en el caso concreto". Machado Martins (2017), p. 233. 
poder jamás modificar este resoluciones judiciales, en caso alguno pretender que se declare la inaplicabilidad de un precepto legal" ${ }^{34}$.

En el derecho comparado, algunos países adoptaron instrumentos procesales distinguiendo entre la casación en el fondo y la casación constitucional, como en el caso de Brasil, surgiendo el recurso especial y el recurso extraordinario, en una estructura que parece más compatible con un sistema de control difuso.

En la misma línea argumentativa, y considerando el principio de competencia institucional de los órganos en conflicto, creemos que la sentencia en análisis no aporta al principio de deferencia que debe presidir las relaciones interinstitucionales. José Ignacio Martínez Estay explica que "a partir de la reforma constitucional de 2005, la deferencia pasó a ser un supuesto de las relaciones del TC no sólo con el legislador y el ejecutivo, sino que además con los jueces ordinarios y especiales. Ello se debe a que la cuestión de inaplicabilidad del artículo $93 \mathrm{~N}^{\circ} 6$ de la Constitución, implica el pronunciamiento del TC respecto de los posibles efectos inconstitucionales derivados de la aplicación de un precepto legal en una gestión judicial seguida ante un tribunal ordinario o especial" ${ }^{35}$, y lo mismo podemos decir en sentido inverso.

El deber de deferencia entre las instituciones debe ser recíproco. De este modo, el deber de deferencia de la Corte Suprema hacia el Tribunal Constitucional implica la autonomía de ambos tribunales para interpretar y aplicar el Derecho en la resolución de los conflictos sometidos a ellos ${ }^{36}$.

También es cierto que el Tribunal Constitucional se ha confundido en su ejercicio autónomo, como se constata en la parte decisoria del fallo de Inaplicabilidad No 5.912-2019, en la que de modo impropio ha determinado que "cumpla la Excelentísima Corte Suprema, una vez concluida la gestión pendiente, con informar a esta magistratura la forma efectiva en que se dio cumplimiento a esta sentencia”. No hay en nuestro ordenamiento jurídico un vínculo orgánico entre ambos tribunales que permita al Constitucional exigir comprobaciones del cumplimiento de

\footnotetext{
34 Mosquera Ruiz y Maturana Miquel (2010), p. 296. En sentido contrario, Ried Undurraga entiende que "Respecto de las sentencias civiles, la jurisprudencia de la Corte Suprema ha negado sistemáticamente la anulación de un fallo cuando la causal de casación es la infracción a un precepto constitucional. A este respecto, los profesores de Derecho procesal Mario Mosquera y Cristián Maturana, en su conocido Tratado sobre los recursos procesales hacen suyo el criterio de Fernando Atria, que a su vez recoge una tendencia jurisprudencial arraigada”. En Ried UndurRaga (2015), p. 274. En el mismo sentido: Romero et alii (2008), p. 237.

35 Martínez Estay (2015), p. 238.

36 Martínez Estay (2015), p. 239.
} 
sus decisiones. Por cuanto carece de facultades ejecutivas, ya que su rol se agota con los efectos declarativos de sus decisiones, debido su especial competencia.

\section{La cosa juzgada constitucional y la imposibilidad de su revisión vía recurso de protección}

La Constitución Política dispone en su artículo 94 que contra las resoluciones del Tribunal Constitucional no procederá recurso alguno, sin perjuicio de que puede, el mismo Tribunal, conforme a la ley, rectificar los errores de hecho en que hubiere incurrido. Por otro lado, el artículo 41 de la Ley Orgánica del Tribunal Constitucional establece que contra las resoluciones del Tribunal no procederá recurso alguno. El Tribunal, de oficio o a petición de parte, podrá modificar sus resoluciones solo si se hubiere incurrido en algún error de hecho que así lo exija. Ambos dispositivos normativos no utilizan la expresión "cosa juzgada" para determinar la imposibilidad de recursos, y por esta razón, la negativa por parte de la doctrina de su reconocimiento ${ }^{37}$.

La doctrina de la cosa juzgada está presente en todo ordenamiento jurídico occidental. Esto es así porque la doctrina de la cosa juzgada es un principio universal que garantiza la seguridad jurídica de los sistemas jurídicos ${ }^{38}$. De este modo, "toda sentencia despliega los efectos de cosa juzgada formal cuando ya no puede ser recurrida ni puede presentarse la queja por inadmisión ni puede ser impugnada de otro modo" 39 . No obstante, el proceso persigue una sentencia vinculante que decida el conflicto y con esto establezca la seguridad y la paz jurídica entre las partes. La prohibición de modificar el contenido de la sentencia por fuerza de la cosa juzgada formal no es suficiente, dado que el resultado del proceso carecería de sentido si la litis fuera eterna, es decir, no terminara nunca.

Francesco Carnelutti define la cosa juzgada como "el fallo de mérito que se obtiene mediante el proceso de cognición, o en otros términos, el fallo sobre las cuestiones de fondo" ${ }^{40}$. La fuerza de cosa juzgada material protege el contenido de la sentencia en caso de identidad de objetos entre el primero y segundo procesos

37 Machado Martins (2017), p. 102.

38 "Empirically, every system of justice around the world, from near its beginnings, has generated a common core of res judicata law to make adjudications binding. "The doctrine of res judicata is a principle of universal jurisprudence forming part of the legal systems of all civilized nations”. En: CLERMONT (2016), p. 1079.

39 Hess y Jauernig (2015), p. 359.

40 Carnelutti (1997), p. 136. 
[...]. En consecuencia, la cosa juzgada impide tanto la condena como el pronunciamiento contrario, pero su principal función es su carácter prejudicial para el nuevo proceso ${ }^{41}$.

La sentencia del Tribunal Constitucional no es diferente, pues se reviste de la calidad de la cosa juzgada ${ }^{42}$. La formación de la cosa juzgada se debe primeramente a la naturaleza del tribunal, -de única instancia-, no teniendo superior jerárquico con competencia especial para revisar sus decisiones ${ }^{43}$. Sólo del mérito de la lectura del texto constitucional anteriormente mencionado y también la Ley Orgánica del Tribunal Constitucional, podemos asegurar que no existe ningún vacío normativo. En efecto, tanto el artículo 94, de la Constitución Política de la República como el artículo 41 de la referida Ley Orgánica, establecen sin lugar a dudas la cosa juzgada constitucional. Tanto es así que Williams Valenzuela explica que "en efecto, debemos comenzar señalando que el fallo de inaplicabilidad produce cosa juzgada material y formal, es decir, representa un acto jurídico procesal del Tribunal Constitucional de única instancia, irrecurrible, inalterable y vinculante" 44 .

Es evidente también que la cosa juzgada no lleva a la petrificación de la interpretación constitucional, "puesto que es posible que cambie de posición frente a una nueva circunstancia de hecho o una nueva causa de pedir ${ }^{45}$, regla propia del rebus sic stantibus.

De este modo, la Corte Suprema no puede crear por vía jurisprudencial un mecanismo de revisión de las decisiones del Tribunal Constitucional, pues estaría

41 Hess y Jauernig (2015), p. 361.

42 En sentido contrario: "en un primer análisis no es muy difícil darse cuenta que en nuestra CPRCh no hay norma alguna que de manera directa o indirecta, expresa o implícita aluda a institución de la cosa juzgada, así como tampoco respecto al efecto de las sentencias del TCCh en materia de inaplicabilidad. Lo mismo puede predicarse respecto de la declaración de inconstitucionalidad. Los efectos de esta última, son consecuencia de la invalidación del precepto legal declarado previamente inaplicable, ahora inconstitucional". En Garrote Campillay (2012), p. 398.

43 En sentido contrario: "no es la cosa juzgada la que opera efectos 'erga omnes', sino los efectos directos de la sentencia. Todos quedan sometidos a la decisión por la circunstancia de no poder discutir la constitucionalidad de la ley en abstracto. Una vez decidida la (in)constitucionalidad de la ley, nada puede ser hecho por los ciudadanos o por todos los que son representados por los legitimados al control abstracto. Están ellos sometidos a la decisión, siendo imposible su cuestionamiento en cualquier acción concreta. Manténgase el punto: la estabilidad de la decisión no deriva de la imposibilidad de destinarse a cuestionar la constitucionalidad, sino de la imposibilidad en discutirla y de la sumisión tomada por el Tribunal constitucionalmente legitimado para definirla. En MARINONI (2013), p. 234.

44 Valenzuela Villalobos (2019), p. 64.

45 Machado Martins (2017), p. 104. 
afectando directamente la cosa juzgada constitucional. En este caso, una de las partes podría invocar el recurso de revisión por fuerza del artículo 810, n. $4^{\circ}$ del Código de Procedimiento Civil.

\section{Conclusiones}

La Corte Suprema vía decisión jurisdiccional ha por medio de esta decisión transformado la naturaleza de acción judicial para recurso extraordinario. En el derecho procesal brasileño, el recurso extraordinario es el acto jurídico procesal que tiene por objeto impugnar una decisión judicial dictada por un tribunal de primera o de segunda instancia, que contraría directa y frontalmente el sistema normativo establecido en la Constitución y tiene por objetivo la unidad de la interpretación de la Constitución.

Si bien es cierto que la Corte Suprema niega expresamente que la acción de protección funcionaría como un recurso procesal ${ }^{46}$, en definitiva, la forma como lo ha concebido, genera una posibilidad de revisión de las sentencias del Tribunal Constitucional.

El recurso de protección es una acción de naturaleza sumarísima que tiene por objeto la tutela de los derechos fundamentales y no está diseñada, conforme a lo anteriormente mencionado, como un recurso procesal. Esto se debe a que no obedece a ninguno de los principios propios de un sistema recursivo.

Por otro lado, la posibilidad de revisar las sentencias del Tribunal Constitucional por vía de recurso de protección atentaría directamente a la cosa juzgada constitucional. De este modo, entendemos que la Corte Suprema no puede crear por vía jurisprudencial un mecanismo de revisión de las decisiones del Tribunal Constitucional, pues estaría afectando directamente la cosa juzgada constitucional.

\section{Bibliografía citada}

Aragón, M. (2004): "Problemas del Recurso de Amparo", en A.A.V.V, La reforma del Recurso de Amparo (Valencia, Tirant lo Blanch), pp. 148 y ss.

46 Posteriormente, la Corte Suprema ha negado admisibilidad a un recurso de protección en contra de sentencia del Tribunal Constitucional. En: Corte Suprema, Rol No 29.256-2019, sentencia de 22 de octubre de 2019. 
Bordalí SAlamanca, Andrés (2006): “El recurso de protección entre exigencias de urgencia y seguridad jurídica”, en Rev. derecho (Valdivia), (Vol. 19, № 2), p. 205-228.

Bordalí Salamanca, Andrés (2011): "El recurso de protección chileno al banquillo", en Revista IUS, (Vol. 5, No 27), p. 56-71.

Cadiet, Loïc; Jeuland, Emmanuel (2017): Droit judiciaire privé (10 a edición, Paris, LexisNexis).

Carnelutti, Francesco (1997): Instituciones del proceso civil (Buenos Aires, El Foro), tomo I.

Clermont, Kevin M. (2016): “Res judicata as requisite for justice”, en Rutgers University Law Review (Vol. 68), pp. 1067-1139.

Couchez, Gérard (1998): Procédure civile (Paris, Dalloz).

Delgado Castro, Jordi (2012): “El recurso extraordinario en el Proyecto de Código Procesal Civil”, en Revista Ius et Praxis, (Año 18, No 2), pp. 125-146.

GANDUlFo R., Eduardo (2009): "Sobre preclusiones procesales en el derecho chileno en tiempo de reformas: ensayo de una teoría general desde un enfoque valorativo jurídico", en Revista Ius et Praxis, (Año 15, No 1), pp. 121-189.

Garrote Campillay, Emilio Alfonso (2012): “Cosa juzgada constitucional sui generis y su efecto en las sentencias del Tribunal Constitucional en materia de inaplicabilidad e inconstitucionalidad", en Revista Estudios Constitucionales (Año 10, No 2), pp. 391-428.

GiLsanz Usunaga, Javier (2016): "El certiorari ante el Tribunal Supremo americano: una aproximación desde el derecho español”, en Cuadernos de Derecho Transicional (Vol. 8, No ${ }^{\circ}$ ), pp. 125-149.

Goodnow, Frank (1891): “The Writ of Certiorari”, en The Academy of Political Science (Vol. 6, No. 3), pp. 493-536.

Hazard JR., Geoffrey C.; TARuffo, Michele (2006): La justicia civil en Estados Unidos (Traducc. F. Gascón Inchausti, Navarra, Thomson Aranzadi).

Hess, Burkhard; JAUernig, Othmar (2015): Manual de derecho procesal civil (Madrid, Marcial Pons).

Luiso, Francesco P. (2013): Diritto processuale civile ( $7^{\text {a }}$ edición, Milano, Giuffré), tomo II.

Luiso, Francesco P. (2017): Diritto processuale civile (9ª edición, Milano, Giuffré), tomo I. 
Machado Martins, Priscila (2017): La cosa juzgada constitucional (Madrid, Reus).

Marinoni, Luiz Guilherme (2013): "Efectos de las decisiones de inconstitucionalidad y de constitucionalidad en el derecho brasileño", en MARINONI, Luiz Guilherme (org.), Derecho procesal constitucional brasilero (México, Porrúa).

Marinoni, Luiz Guilherme; Arenhart, Sergio Cruz; Mitidiero, Daniel (2015): Curso de Processo civil (São Paulo, Revista dos tribunais), Vol. II.

Martínez Estay, José Ignacio (2015): "La deferencia del Tribunal Constitucional respecto del juez de la gestión pendiente en la cuestión de inaplicabilidad", en Estudios constitucionales (Año 13, No 1), pp. 237-270.

Mosquera Ruiz, Mario; Maturana Miquel, Cristián (2010): Los recursos procesales (Santiago, Editorial Jurídica de Chile).

Nogueira Alcalá, Humberto (1999): "El recurso de protección en Chile”, en Anuario Iberoanericano de Justicia Constitucional (No 3), pp. 157-180.

Nogueira Alcalá, Humberto (2003): "Los Tribunales Constitucionales de Sudamérica a principios del siglo XXI”, en Revista Ius et Praxis, (Año 9, oo 2), pp. 59-131.

NúÑEZ OJEDA, Raúl (2008): "El sistema de recursos procesales en el ámbito civil en un Estado Democrático Deliberativo", en Revista Ius et Praxis (Año 14, №1), pp. 199-223.

Pardow Lorenzo, Diego G.; Verdugo Ramírez, Sergio (2015): “El Tribunal Constitucional chileno y la reforma de 2005: Un enroque entre jueces de carrera y académicos", en Revista de derecho (Valdivia), (Vol. 28, № 1), pp. 123-144.

Rangel Dinamarco, Cândido (2009): A instrumentalidade do processo (14 ${ }^{\mathrm{a}}$ edición, São Paulo, Malheiros).

Ried Undurraga, Ignacio (2015): "El recurso de protección como control de constitucionalidad de las resoluciones y sentencias civiles, en respuesta a la ineficacia de la acción de inaplicabilidad por inconstitucionalidad”, en Revista Estudios Constitucionales (Año 13, No 1), pp. 271-320.

Romero Seguel, Alejandro; Aguirrezabal Grünstein, Maite; Baraona GonZÁLEZ, Jorge (2008): "Revisión crítica de la causal fundante del recurso de casación en el fondo en materia civil", en Revista Ius et Praxis, (Año 14, № 1), pp. 225-259. 
Satrústegui Gil-Delgado, Miguel (2009): "La Magna Carta: realidad y mito del constitucionalismo pactista medieval", en Historia Constitucional, ( $\left.\mathrm{N}^{\circ}{ }_{10}\right)$, pp. 243-262.

Silva Irarrázaval, Luis Alejandro (2012): “¿Es el Tribunal Constitucional el supremo intérprete de la Constitución?", en Revista de Derecho de la Pontificia Universidad Católica de Valparaíso ( $\mathrm{N}^{\circ} 38$ ), pp. 573-616.

\section{Jurisprudencia citada}

Confederacion Nacional De Funcionarios con Tribunal Constitucional (2019): Corte Suprema, sentencia de 07 de octubre de 2019 (recurso de protección), Rol No 21.027-2019.

Farbán con Tribunal Constitucional (2019): Corte Suprema, sentencia de 22 de octubre de 2019 (recurso de protección), Rol No 29.256-2019. 
